\title{
Fuzzy logic in decision support system as a simple Human/Internet of Things interface for shunt active power filter
}

\author{
M. JASIŃSKI ${ }^{1 *}$, P. MAJTCZAK ${ }^{1}$, and A. MALINOWSKI ${ }^{2}$ \\ ${ }^{1}$ Institute of Control and Industrial Electronics, Warsaw University of Technology, 75 Koszykowa St., 00-662 Warsaw, Poland \\ ${ }^{2}$ Electrical and Computer Engineering Department, Bradley University, Peoria, IL 61625, USA
}

\begin{abstract}
This paper introduces a fuzzy logic (FL) based decision support system (DSS) for a three-phase bidirectional AC-DC grid converter, working in a modern grid-like smart grid or smart industry. It is assumed that the appliances connected to that grid interact as in the Internet of Things (IoT) or like in the Internet of Everything (IoE) i.e. with a human being located in the chain of data flow. A power electronics AC-DC converter, operating as a shunt active power filter (SAPF) is selected for the case study. A harmonics reduction algorithm is presented as an implementation sample of the DSS. The operation of the SAPF is described and analysed. Experimental results showing the tuning process and operation of the laboratory model are also presented and discussed. Finally, it is shown that the DSS is an elegant and intuitive interface, which can simplify a human's or machine's decision-making process. Thanks to the DSS, the meaning of transferred data is translated into linguistic variables that can be understood by non-experts. Hence, it is expected that the amount of transferred data in the smart grid and in the IoE would be reduced. But in the same time, the high quality of the controlled process is retained, as shown by the example of a conventional SAPF.
\end{abstract}

Key words: fuzzy logic, decision support system, shunt active power filter, power quality, smart grids, smart industry, harmonics compensation, Internet of Things, Internet of Everything.

\section{Introduction}

Nowadays, considering the increasing number of power electronics devices and different kinds of loads connected to the common grid, the power quality (PQ) issue becomes very important. Higher order harmonics, generated by nonlinear loads connected to the grid, cause serious disturbances of the PQ and have a negative impact on energy consumers. Expected PQ criteria are described in power quality standards and system operators' grid codes. Conventionally, in order to fulfil the PQ requirements established by grid codes including reduction of high order harmonics, passive filters are used. These filters have several disadvantages [1]:

- one filter is needed for each harmonic,

- risk of occurring of the resonance phenomenon,

- reactive power consumption,

- aging of the additional elements,

- size, weight and cost of passive components,

- no interaction with software.

The shunt active power filter (SAPF) is another solution that allows for reduction of higher order harmonics that do not have the limitations of passive filters. With a proper control algorithm, the SAPF can be used to compensate the reactive power and to reduce higher order harmonics of the current. Moreover, the device is able to operate in the uncertain environment with respect to the system dynamics. Studies show that the presented robust direct-power control with space vector modulation (RDPC-SVM) can fulfil the requirements of sinusoidal and balanced currents

*e-mail: marek.jasinski@ee.pw.edu.pl under distorted and unbalanced grid voltages [2]. The increasing role of distributed generation causes increasing requirements and functionalities expected from the SAPF established by different grid codes and PQ standards, and to fulfil them, more complex and advanced control strategies are needed [3-7].

The design and tuning rules for such control algorithms usually require expert knowledge of different fields of science (mathematics, instrumentation, control theory, power electronics, cyber-physical systems) [8,9], and of the electrical power market (PQ standards and regulations, and economics profile) $[10,11]$. In the case of modern electric power grids, and especially in the case of smart grids, the requirements for grid converters (GCs) can change according to the actual grid states. Many methods have been proposed to simplify the interaction of GCs with the grid. However, most of them are focused only on power flow and PQ control $[2,4]$. According to the authors' knowledge, there are no "user-friendly" solutions to simplify this process.

Fuzzy logic (FL) has already proved to be useful as a current and voltage controller [12-15]. However, in the context of this paper, the role of FL is focused on flexible and reliable user-SAPF interface that is capable of transferring user requirements to grid code needs using linguistic variables for data exchange in a fast and quite straightforward manner [16].

The objective of this paper is to propose a simple solution for interaction between the SAPF and a human (non-expert in power electronics), and/or a machine (not constructed by a power electronics specialists). Use of FL is one of the possible solutions, and can be applied to implementation of the control interface of the SAPF. It allows for adopting control rules to the continuously changing grid codes, economic situation, PQ standards, etc. 
The innovative value of the presented work lies in the application of FL as an interface between high-bandwidth power electronics converter's control method, and a human and/or a machine. The meaning of data sent from/to the device could be easily understood by a human operator. It should be easy to comprehend also thanks to the reduction of the amount of exchanged data. The decision support system (DSS)-based FL laboratory investigation on simple-current higher harmonics attenuation shows very good results and proves the DSS's potential for further research in the Internet of Things (IoT) application.

It should be noted that the presented results are preliminary with respect to the FL human and IoT interface friendly concept. The research on the subject is being continued and will be integrated with a multi-objective optimization $[17,18]$ process of the $\mathrm{GC}$, where not only hardware, but also software assumptions have an impact on overall efficiency, reliability, and functionality of the GC.

This paper is focused on GC operated as SAPF, and it is organized as follows: an introduction with problem description and basics knowledge about SAPF and its control requirements, a brief overview of literature regarding power quality, FL, the IoT and its multidisciplinary character, the main issues and the thesis of the paper, and the paper contest. Then, a brief description of IoT and Internet of everything (IoE) is provided. In the next chapter, SAPF and selected control issues are addressed, and a new concept of control is proposed. The subsequent chapter is devoted to the proposed DSS algorithm implementation based on RDPC-SVM with higher harmonics compensator (HC). Finally, the experimental results, conclusions, and references are provided.

\section{Description of the Internet of Things (IoT)}

The IoT is multidisciplinary by its nature, as it is shown in Fig.1. Because of a great number of different devices that exchange information, there is a great need for standardization and for the development of a universal platform that would translate specific problems into language easy enough to be understood by everyone and everything, without the need for complex

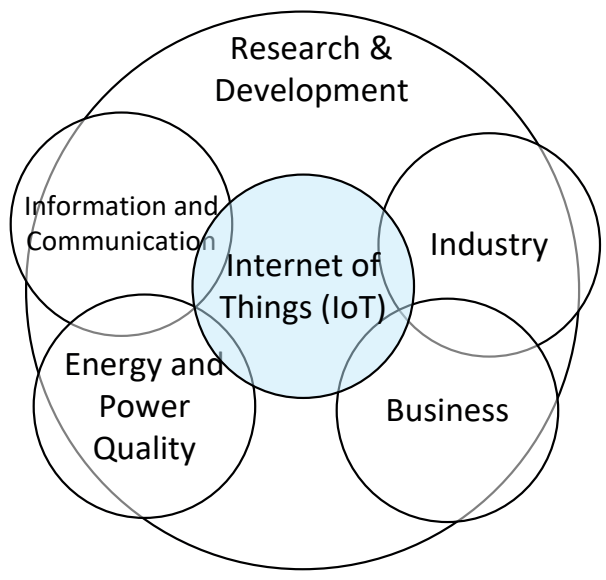

Fig. 1. Internet of things (IoT) concept

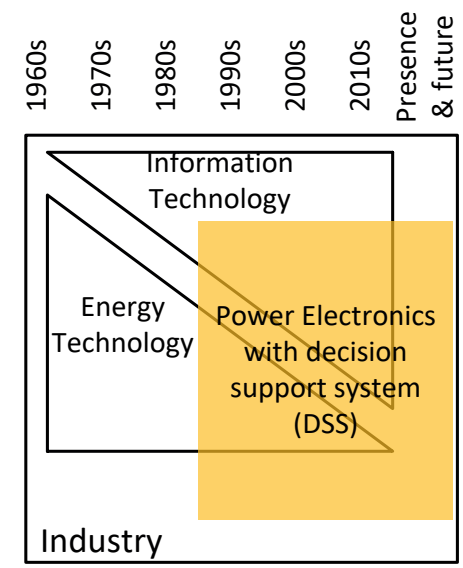

Fig. 2. A brief concept of a decision support system (DSS) application as an SAPF in smart industry

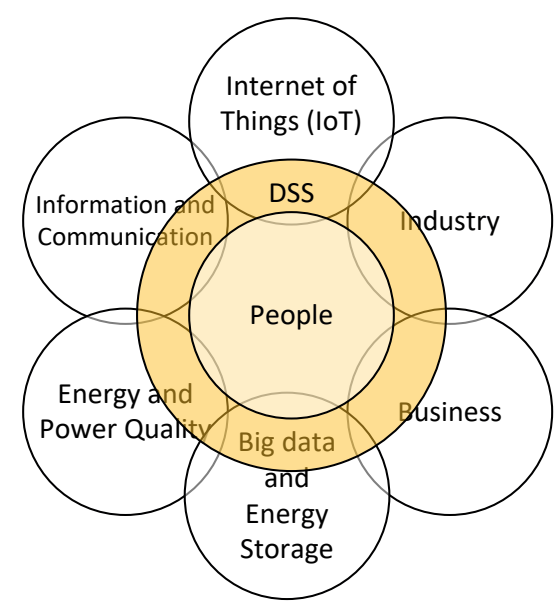

Fig. 3. Internet of everything (IoE) with decision support system (DSS)

computations. For example, the generalized specification of excellent power quality or pure power quality is preferred to the information that total harmonics distortion of the voltage and current is below $1 \%$ or above $10 \%$, etc.

The initial research presented here proves the concept of simplicity of the proposed DSS. This solution can be implemented especially in the smart industry area, where a lot of SAPFs already operate. Because DSS is a software solution and does not change the main control structure, it can also be added to older devices, as long as there is sufficient additional computational capacity. The computational capacity of power electronics-SAPF was significantly increased in the last three decades.

Fig. 2. presents a brief concept of DSS application in smart industry for SAPF. Considering the facts mentioned above, it can be concluded that there is market demand for the development of a universal and easy-to-understand interface among people, machines, things, and processes in the areas of applications such as industry, grids, cities, homes etc. (Fig. 3). Therefore, the IoE [19] challenge can be simplified thanks to the proposed DSS, and the amount of transferred data can be reduced and converted to linguistic variables, well understood by most potential users. 


\section{Shunt active power filter and control issues}

The principle of SAPF operation is based on the generation of the appropriate current required to compensate for the distortion caused by the non-linear load. Fundamental equation describing it is given by (1).

$$
I_{\text {line }}=I_{S A P F}+I_{\text {load }}
$$

where: $I_{S A P F}-$ current supplied by SAPF, $I_{\text {line }}$ - grid current in point of common coupling (PCC).

Fig. 4. shows the block diagram of the analysed system with SAPF and nonlinear load. Also, power flow in the analysed system with SAPF operating under sinusoidal grid voltage condition is shown. The active power $P$ generated by the source is delivered to the non-linear load. Power $P$ is composed of the fundamental component of voltage and current. Additionally, small amounts of power $S_{D C \text {-link }}$ are transferred to the DC-link of the SAPF to maintain its voltage around the reference voltage. $S_{\text {comp }}$ power is delivered by the SAPF to the load in a way that compensates the whole reactive power.

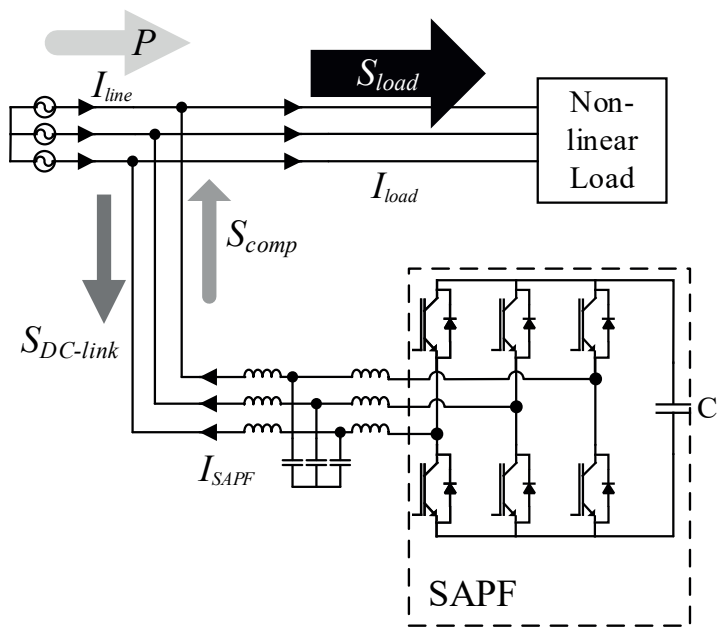

Fig. 4. Analysed system with SAPF and non-linear load with power flow

Power quality standards and grid codes establish rules and regulations for acceptable harmonic distortion in power systems. Table 1 presents the relevant requirements of the grid regulation [20]. Table 2 shows related harmful effects caused by low power quality.

In 1922, Jan Łukasiewicz, Polish logician and philosopher, presented truth-tables with finitely and infinitely many truth-solutions, according to the principles where the truthvalues are numbers over the interval $[0,1] .43$ years later, in 1965, Lotfi Zadeh presented the original paper formally defining fuzzy logic theory [22]. Fuzzy logic is the precise logic of imprecision and approximate reasoning. A fuzzy model consists of multiple if-then rules (2) that describe the interaction between linguistic variables instead of numerical ones.
Table 1

Polish operator's grid code IRiESD [20]

\begin{tabular}{|l|l|l|l|}
\hline \multicolumn{4}{|c|}{ Current harmonics for three-phase loads $\leq 16 \mathrm{~A}$} \\
\hline $\begin{array}{c}\text { Odd } \\
\text { harmonics }\end{array}$ & $\begin{array}{c}\text { Max. value } \\
{[\mathrm{A}]}\end{array}$ & $\begin{array}{c}\text { Even } \\
\text { harmonics }\end{array}$ & $\begin{array}{c}\text { Max. value } \\
{[\mathrm{A}]}\end{array}$ \\
\hline 3 & 2.3 & 2 & 1.08 \\
\hline 5 & 1.14 & 4 & 0.43 \\
\hline 7 & 0.77 & 6 & 0.3 \\
\hline 9 & 0.4 & $15 \leq \mathrm{n} \leq 39$ & $0.23(8 / \mathrm{n})$ \\
\hline 11 & 0.33 & & \\
\hline 13 & 0.21 & & \\
\hline $15 \leq \mathrm{n} \leq 39$ & $0.15(15 / \mathrm{n})$ & & \\
\hline
\end{tabular}

Table 2

Harmful effects of harmonics and practical limits [21]

\begin{tabular}{|c|c|c|}
\hline Equipment & Effects & Limits \\
\hline $\begin{array}{l}\text { Power } \\
\text { capacitors }\end{array}$ & $\begin{array}{l}\text { Overheating, premature } \\
\text { ageing (breakdown), } \\
\text { resonance. }\end{array}$ & $\begin{array}{l}\text { I }<1.3 \mathrm{In} \text {, } \\
(\mathrm{THD}<83 \%) \\
\text { or } \mathrm{U}<1.1 \mathrm{Un} \text { for } \\
8 \text { hours/days } \\
\text { at low voltage }\end{array}$ \\
\hline Transformers & $\begin{array}{l}\text { Losses (ohmic-iron) and } \\
\text { excessive overheating. } \\
\text { Mechanical vibrations. } \\
\text { Noise pollution. }\end{array}$ & \\
\hline Circuit breakers & Unwanted tripping & $\mathrm{U}_{\text {harm }} / \mathrm{U}_{1} ; 6$ to $12 \%$ \\
\hline $\begin{array}{l}\text { Power } \\
\text { electronics }\end{array}$ & $\begin{array}{l}\text { Problems related to } \\
\text { waveform (commutation, } \\
\text { synchronization). }\end{array}$ & \\
\hline
\end{tabular}

$$
\text { if ( } x \text { is } A i) \text { and ( } y \text { is } B i) \text {, then }(z \text { is } C i) \text {, }
$$

where $\mathrm{x}, \mathrm{y}, \mathrm{z}$ are process state variables (crisp-values) associated with $A_{i}, B_{i}$, and $C_{i}$ fuzzy sets (linguistic values) [16, 23, 24].

The output fuzzy set $C_{i}$ has a membership function $m_{C i}(z)=\min \left(m_{C i}(z) \tau_{i}\right)$. The obtained membership functions are combined into one fuzzy output distribution. This is usually done by $m_{\text {out }}(z)=\max \left(m_{C i}(z)\right)$ (fuzzy "or" operation). The output of the inference procedure $m_{\text {out }}(z)$ is often desired to be a crisp value. This operation is called defuzzification. It may be accomplished by several methods, such as mean-of-maximum (MOM), centre-of-sums (COS), centre-of-mass (COM), or others [25-27]. The choice of defuzzification procedure is derived from a compromise between accuracy and computational effort. The output crisp value is calculated as the centre of the area below the combined membership function $m_{\text {out }}(z)$. The defuzzification with the use of COM method is presented in this paper. 


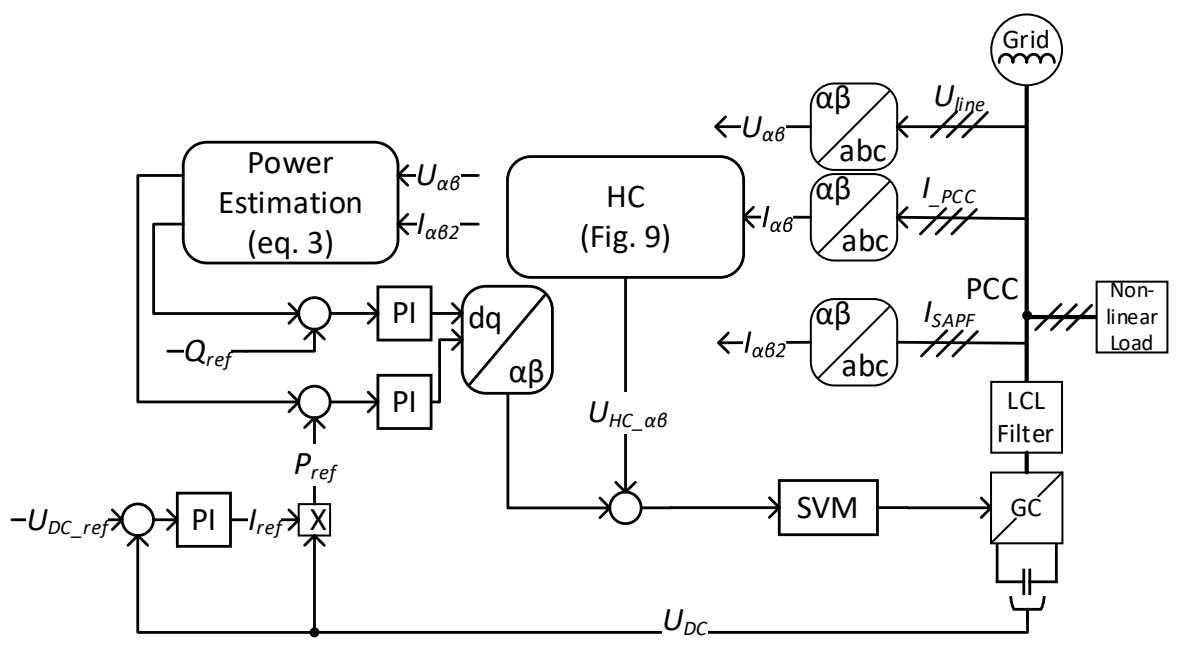

Fig. 5. Block diagram of the implemented control strategy based on robust direct power control with space vector modulation (RDPC-SVM) and harmonics compensation (HC) for GC. According to needs it can operate as SAPF or interface for distributed generation (DG) sources [32]

\section{Proposed algorithm implementation}

4.1. Control algorithm. In our example, the output power and DC-link voltage of the SAPF are controlled by the RDPC-SVM algorithm $[2,28,29]$. The block diagram of the applied control strategy divided into power estimation, power and DC-link voltage control, and higher harmonics compensation (HC) block is presented in Fig. 5. Additional functions, such as dips compensation, power feed-forward, and impedance estimation are not used for the purpose of this paper. However, it should be stressed that FL could be also applied to tune and change assumption under voltage dips or "weak grid" condition. The HC block is implemented using an integral controller [30]. In the analysed case, the DC voltage reference value $\left(U_{D C_{-} R E F}\right)$ is set to $620 \mathrm{~V}$. The reference reactive power, injected by the SAPF during the operation, is calculated and set adjustable to achieve zero phase shift between grid voltage and current. $U_{D C} R E F$ is compared with measured DC-link voltage, and the error is given to DC-link voltage $U_{D C}$ PI controller input. The output of this controller, multiplied by the measured DC voltage provides the reference value of the active power. Reference values of active and reactive powers are compared with values estimated using Akagi's "instantaneous reactive power theory" [31] (3), and are based on the measured grid voltage and current in SAPF.

$$
\left[\begin{array}{l}
P \\
Q
\end{array}\right]=\left[\begin{array}{cc}
U_{\alpha} & U_{\beta} \\
-U_{\beta} & U_{\alpha}
\end{array}\right]\left[\begin{array}{l}
I_{\alpha 2} \\
I_{\beta 2}
\end{array}\right]
$$

The error is fed to the inputs of the PI power controllers. Outputs of the power PI controllers are reference values for the space vector modulator (SVM) [32-35].

Additionally, the same SAPF can operate as an interface between the grid and a disturbed source [2] or an active load. It should be stressed that functionality of GC strongly depends on control algorithm assumptions and current measurements placement. The hardware of the AC-DC converter can be the same, but the values of the passive element (inductances of chokes and capacitances) should be calculated for a specified application $[2,17,28]$.

4.2. Harmonics compensation method. The SAPF requires an additional compensation algorithm in order to reduce current harmonics. Fig. 6 presents a block diagram of such an algorithm based on transformations into synchronous reference frames (SRFs) $[33,36]$. Currents measured in PCC are transformed into stationary reference frame ( $\alpha \beta$ stationary), and then to a synchronously rotating frame (marked as $d q$ ), which synchronously rotates with a selected higher harmonic frequency $n \varphi$.

Each compensated harmonic has a dedicated rotating frame. In the case of this work, the $5^{\text {th }}, 7^{\text {th }}, 11^{\text {th }}$ and $13^{\text {th }}$ harmonics are compensated. Selected signal is filtered by a band-pass filter, which provides information about the amplitude of the harmonic current. The output of the filter is transformed back to the stationary reference frame and summed with other filtered signals. The final signal is added to the main reference voltages for the SVM.

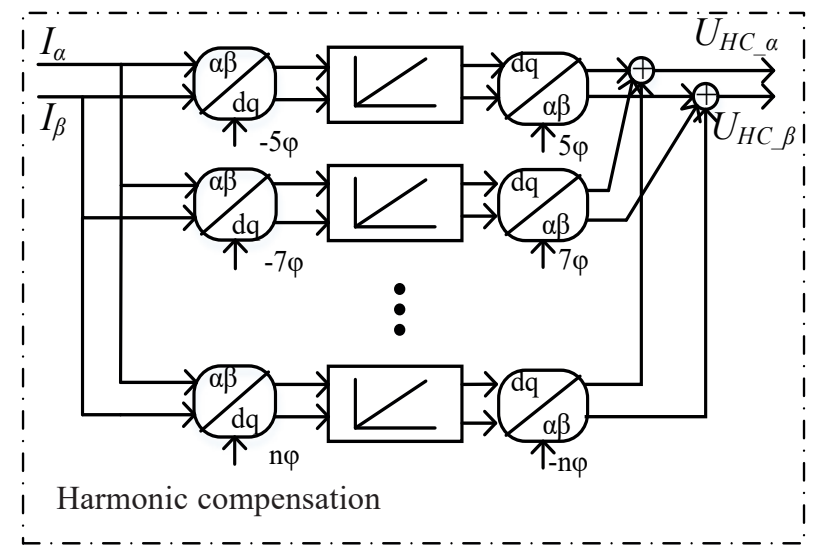

Fig. 6. Harmonic compensation (HC) in SRFs based on integral controller [33] 
a)

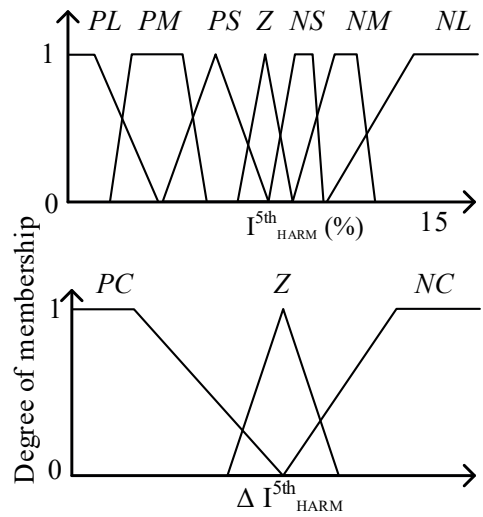

c)

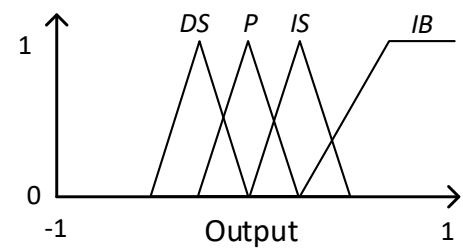

Fig. 7. a) Designed membership functions for $5^{\text {th }}$ harmonic current (input $1(x)$ ), b) Membership functions for change of $5^{\text {th }}$ harmonic current amplitude (input 2(y)), c) Membership functions for decision (output)

4.3. Implemented fuzzy logic algorithm. The FL membership functions were designed using values from Table 1. Fig. 7.a shows designed membership function for the first input. Electrical data is converted into labels "Positive Large (PL)," "Positive Medium (PM)," "Positive Small (PS)," "Zero (Z)," "Negative Small (NS)," "Negative Medium (NM)," "Negative Large (NL)". Second input determines the change of current amplitude (Fig. 7.b) with labels "Negative Change (NC)," "Zero (Z)," "Positive Change $(P C)$." Rules can be designed in MATLAB Fuzzy Logic Toolbox and then imported as source code file to a selected control system.

The T-norm used in antecedent part of rule is minimum of the (4) equation:

$$
\mu_{\mathrm{A} \cap \mathrm{B}}=\min \left(\mu_{\mathrm{Ai}}(\mathrm{x}), \mu_{\mathrm{Bi}}(\mathrm{y})\right) .
$$

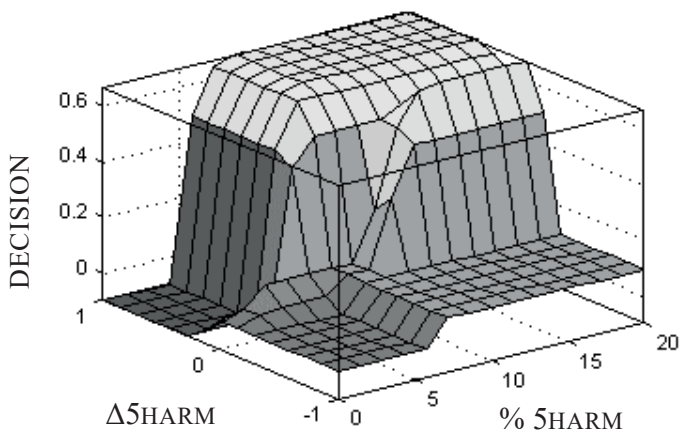

Fig. 8. Surface mapping amplitude to amplitude change of harmonic current
Membership functions are triangular and trapezoid-shaped. The input signal for the FL module is calculated using discrete Fourier transform [37, 38].

The output membership functions are "Decrease Small (DS)," "Proper (P)," "Increase Small (IS)," "Increase Big (IB)" (Fig. 7.c). Figure 8 shows the decision surface for mapping amplitude of harmonic current. The 21 rules proposed in decision support are shown in Table 3.

Table 3

Rules of the DSS

\begin{tabular}{|c|c|c|c|}
\hline$\overbrace{\text { harm }}^{\text {sth }} \Delta^{\text {Sth }}$ harm & $P C$ & $Z$ & $N C$ \\
\hline$P L$ & $D S$ & $P$ & $P$ \\
\hline$P M$ & $D S$ & $I S$ & $P$ \\
\hline$P S$ & $D S$ & $I S$ & $P$ \\
\hline$Z$ & $I B$ & $I S$ & $P$ \\
\hline$N S$ & $I B$ & $I S$ & $I S$ \\
\hline$N M$ & $I B$ & $I S$ & $I S$ \\
\hline$N L$ & $I B$ & $I B$ & $I S$ \\
\hline
\end{tabular}

4.4. Sample application. The rule base was verified using MATLAB Fuzzy Logic Toolbox. Figure 9 shows rules with the highest strength in each inference cycle, in order from the oldest on the top to the newest on the bottom. Numbers on the left are rule numbers defined in the rule base. Columns from left to right show input $l(x), 2(x)$ and output.

In the case shown in Fig. 9, the $5^{\text {th }}$ harmonic current is larger than the required value (NS) and there is no change in its amplitude (Z). The DSS output is $(I S)$. The user changes the gain of the regulator. Current amplitude changed from $(N S)$ to $(Z)$, but the level of compensation is the same $(Z)$, and the output is, again, (IS). In the next step, after the user's interaction input $l(x)$ is still in membership function $(Z)$, but there is $(N C)$ in the input 2(y), then output is $(P)$. A similar situation follows in the next step: input $1(x)$ after fuzzification is $(P S)$, input $2(y)$ is $(Z)$,
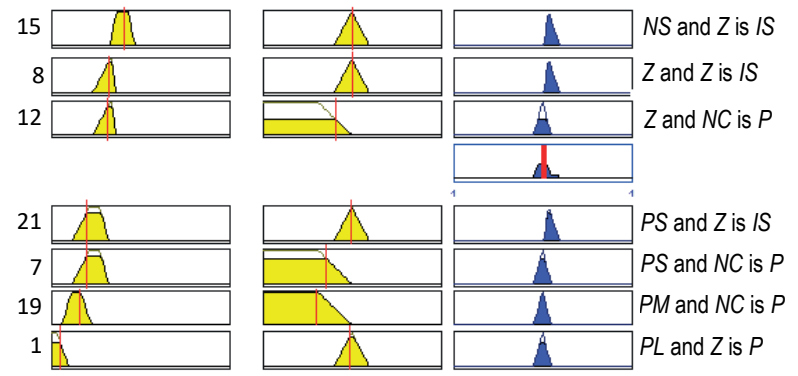

Fig. 9. Rule evaluation using MATLAB's rule viewer. From the left: rule number, input $1(x)$, input $2(y)$, output membership function strengths and rules 
and because of the weak gain of the regulator - the answer is $(I S)$. After increasing the gain, the amplitude further decreases. In the next inference cycle, the rule " $(P S)$ and $(N C)$ is $(P)$ " is strongest. During the next data evaluation, current amplitude is $(P M)$, and still falling $(N C)$. The output is set to $(P)$. Finally, the amplitude is set as $(P L)$, and the change stops $(Z)$. DSS output is $(P)$. The harmonic controller is properly tuned. An interesting case is the evaluation of the rule no. 12. The second input is partially in the sets $(Z)$ and $(N C)$. After that, the inference output $(P)$ is chosen instead of $(I S)$.

\section{Experimental results}

The presented experimental results show a plant configuration aided by DSS, and operation of the SAPF. Parameters of the laboratory setup are presented in Table 4 . The SAPF is connected as shown in Fig. 4.

Table 4

The SAPF experimental Platform Parameters

\begin{tabular}{|l|l|}
\hline Control platform & PC with dSPACE 1103 card \\
\hline Switching frequency & $10 \mathrm{kHz}$ \\
\hline Control algorithm & RDPC-SVM \\
\hline Rated power & $4 \mathrm{~kW}$ \\
\hline Type of Operation & Harmonic Compensation \\
\hline Type of Grid Filter & LCL \\
\hline Grid side inductance & $2.8 \mathrm{mH}$ \\
\hline Input filter capacitor & $2 \mu \mathrm{F}$ \\
\hline Converter side inductance & $5 \mathrm{mH}$ \\
\hline Nominal Grid Voltage & $230 \mathrm{~V}$ \\
\hline Nominal DC-Link Voltage & $620 \mathrm{~V}$ \\
\hline DC-Link Capacitance & $470 \mu \mathrm{F}$ \\
\hline Diode rectifier load & $100 \Omega$ \\
\hline Diode rectifier input inductance & $10 \mathrm{mH}$ \\
\hline Diode rectifier DC-link capacitor & $750 \mu \mathrm{F}$ \\
\hline
\end{tabular}

5.1 Implementation of the fuzzy logic procedure. In this case, the DSS is supposed to aid the user with tuning the selective harmonic compensator. The DSS is implemented independently from the selected PQ control algorithm, and requires only the defined input variables. In Fig. 10, the inner circles operate with higher sampling times than the outer ones. Hence, the lowest sampling time can be used for DSS. Based on input variables and an inference machine, the output variables are obtained for either the operator or machine.

The DSS is called in the interrupt service routine ISR1 with reduced frequency of $2.5 \mathrm{kHz}$. Fig. 11 presents the flow diagram of the DSS. The experiment is focused on the fifth harmonic regulator. Figures 12.I-IV are arranged in the same manner. Part a) of the figure shows fuzzy logic interface, while part b) shows the corresponding oscillograms. To be more specific, part

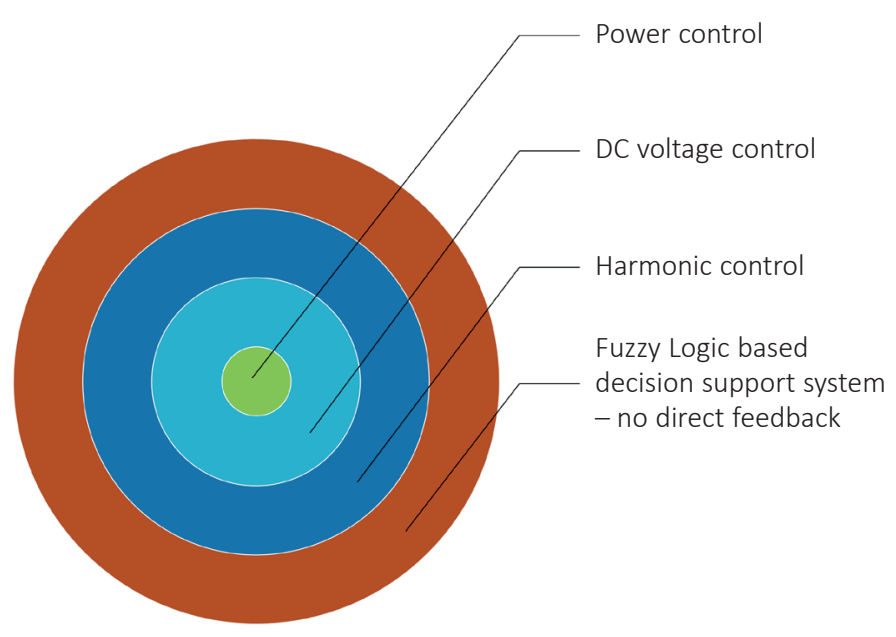

Fig. 10. Decision support system (DSS) implementation in SAPF control structure

a) consists of two waveforms showing the actual input $(x, y)$, inference results, and FFT. Part b) shows the system voltages and currents. Shown from the top, always in the same order: grid voltage of phase A, converter DC-link voltage, grid current of phase A, and SAPF's current of phase A.

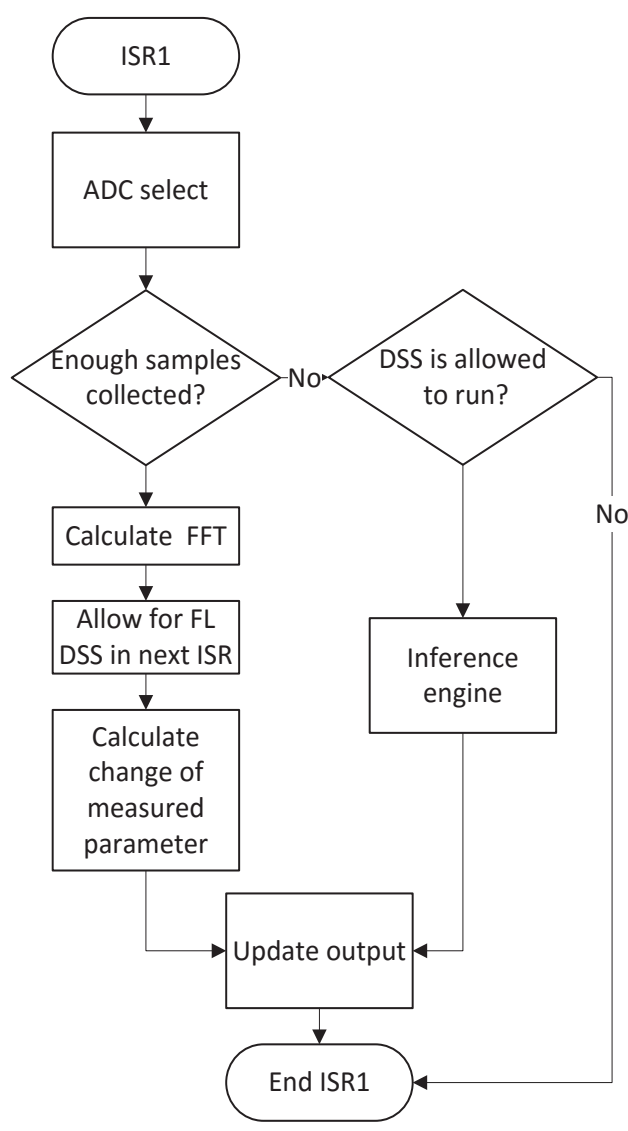

Fig. 11. The DSS flow chart realized in ISR1 with reduced frequency execution to $2.5 \mathrm{kHz}$ 


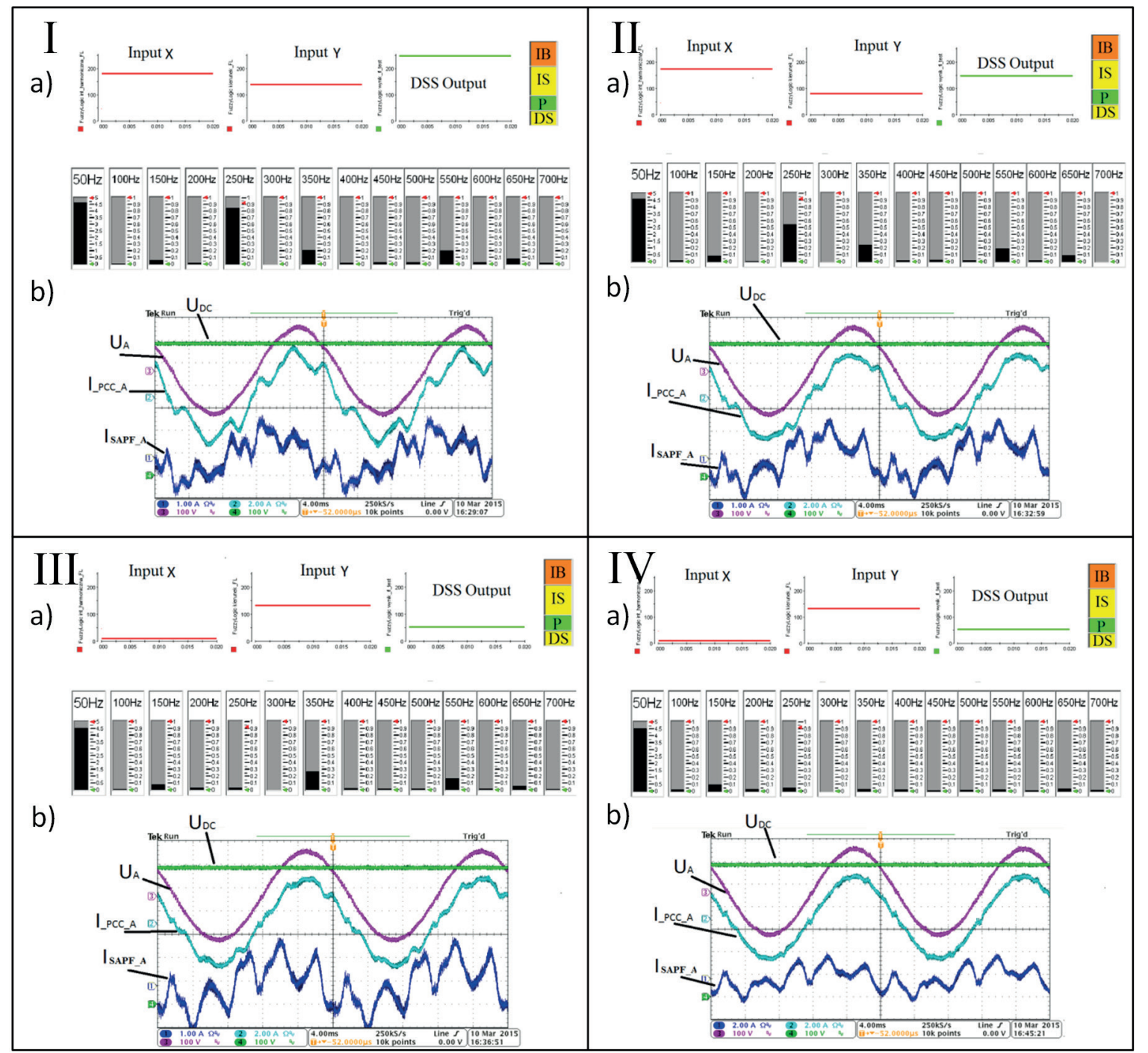

Fig. 12. I) highly disturbed current; II) lowered $5^{\text {th }}$ harmonic amplitude; III) $5^{\text {th }}$ harmonic current is reduced; IV) fully compensated currents of nonlinear load; where: a) DSS interface, b) grid current and voltage waveforms

The initial state of the system is presented in Fig. 12.I, where the disturbance caused by the symmetric nonlinear load is not compensated. The DSS is fed with data from the implemented FFT which is calculated using grid current (at PCC) I_PCC. The amplitude of the fundamental harmonic equals to $4.5 \mathrm{~A}$, and the fifth harmonic current equals to $0.8 \mathrm{~A}$. The measured grid current THD factor is $19.5 \%$. The Fuzzified input for the fuzzy model is $(N L)$ (input $1(x)$ ) and $(Z)$ (input $2(y)$ ). The output is $(I B)$ (as in Tab. 3). According to this, the user should set selective harmonic compensation gain to a high value. This value is calculated in the same manner as for current regulator and provided via the user interface. For the sake of simplicity, the given value is provided only for one chosen higher harmonic.

Through DSS, the operator can enter a new HC regulators' gain value. Fig. 12.II shows the state when SAPF reduces the nonlinear-load higher $\left(5^{\text {th }}\right)$ harmonic current. This is caused by new $\mathrm{HC}$ regulator gains. The old value was $\mathrm{k}_{\mathrm{HC} 5}=0$, and the new one is $\mathrm{k}_{\mathrm{HC} 5}=250$. In this state, the fuzzified value for input $x$ is $(N L)$ because the amplitude of the current is still high, but input $y$ is $(N C)$, which means that the amplitude is decreasing. The DSS induces (IS). The calculated current THD in PCC is $13,8 \%$. Once again does the operator provide the new value for compensator's gain.

Fig. 12.III presents the state where $5^{\text {th }}$ current harmonic is reduced to a very low value ( $1 \%$ of fundamental harmonic). The operator is informed by the DSS that the active filter is properly configured. Current THD in PCC is 7,5\%. Furthermore, the operator can use another rule bases to obtain a lower current THD factor for the $7^{\text {th }}, 11^{\text {th }}$ and $13^{\text {th }}$ harmonics. The procedure must be repeated for each harmonic controller. Sample results are shown in Fig. 12. IV. The THD factor of the obtained current is reduced to $2,94 \%$. When the output of the DSS reaches the value $(P)$, the goal is achieved. The information is then sent to the human or to the machine. 
I) a)

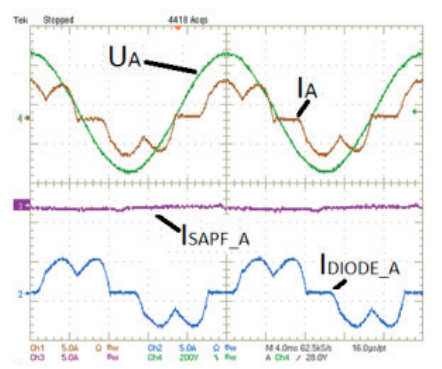

c)

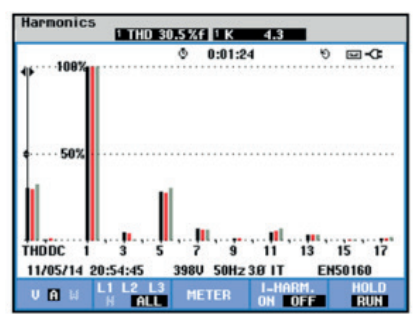

b)

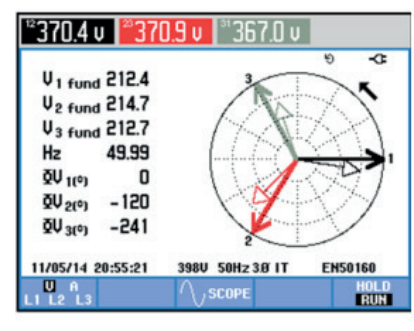

d)

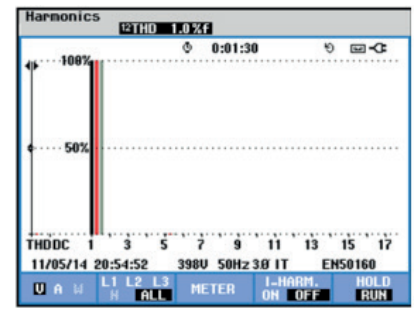

II) a)

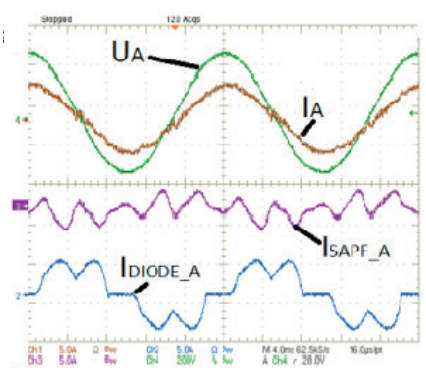

c)

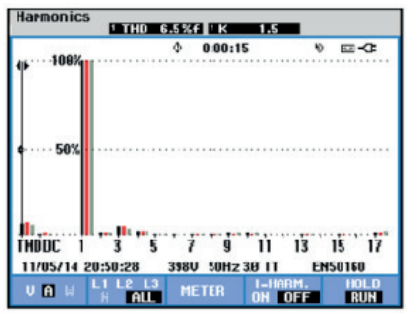

b)

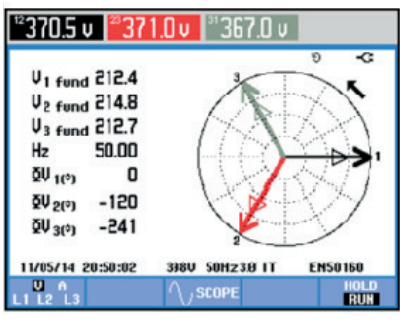

d)

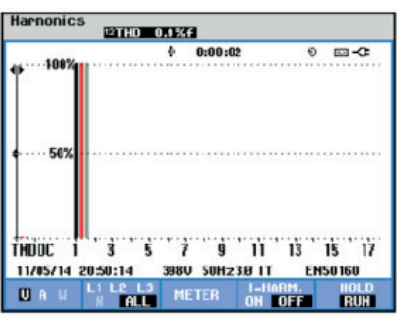

Fig. 13. I) Steady state operation of the SAPF without HC functionality; II) Steady state operation of the SAPF with HC functionality. Where: a) grid current and voltage waveforms, b) phasor plot, c) grid current with THD factor, d) voltage spectrum with THD factor

5.2 Operation of the proposed system. Experimental results show the operation of SAPF tuned with DSS based on FL. The current is disturbed by diode rectifier, connected as shown in Fig. 4. The converter is expected to compensate the current's high-order harmonics. Fig. 13.I and II show the a) Grid's cur-

a)
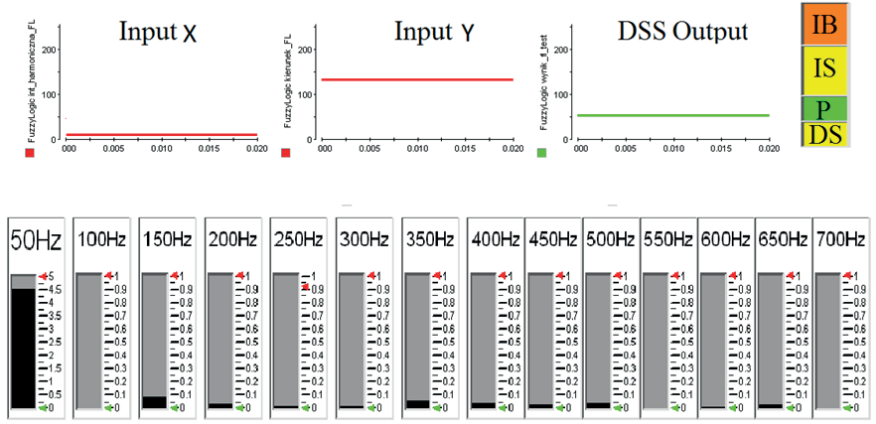

b)

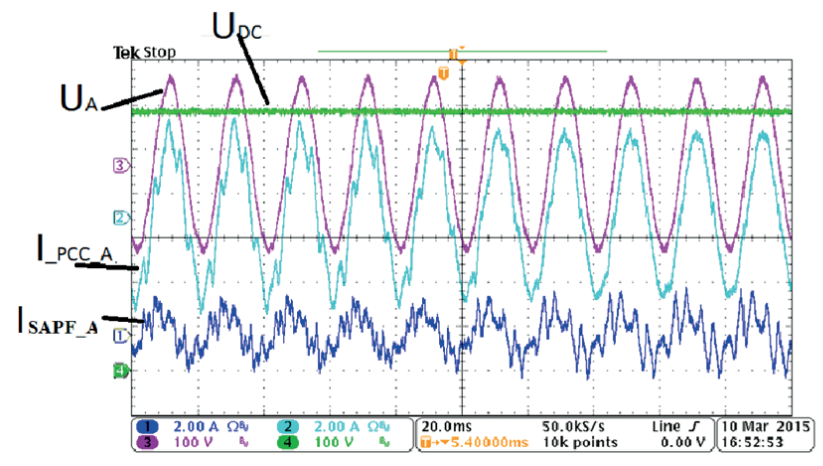

Fig. 14. Transient state after turning on HC functionality. a) DSS interface. b) grid current and voltage waveforms rent and voltage waveforms. From the top: grid voltage and current, SAPF's current, diode rectifier's current, b) phasor plot showing a shift between the voltage and current in PCC, c) grid current spectrum with the THD factor, d) grid voltage spectrum with the THD factor. Fig. 13.I shows the state without an operating SAPF.

Fig. 13.II presents the ability to significantly reduce the grid current higher harmonics by the proposed harmonics compensation method. It can be noted that reactive power is also compensated. The obtained grid current waveforms are balanced and close to sinusoidal shape. Finally, the THD factor of the grid current is significantly reduced. Fig. 14 shows the transient state after turning on SAPF's HC module. It shows that SAPF tuned with the help of the DSS has good dynamics.

\section{Summary and conclusions}

A concept of the SAPF assisted by the fuzzy logic (FL) decision support system (DSS) has been introduced. The control method of the SAPF utilizes robust direct power control with space vector modulation (RDPC-SVM) and higher harmonic compensation (HC). A HC based on the integral controller is described, analysed, and verified by means of experimental investigation. The obtained current waveforms exhibit the desired features, and indicate very good operation of the proposed method (THDi was reduced from $30.5 \%$ to $6.5 \%$ ).

Thanks to FL, the proposed DSS algorithm assures:

- Help in determination of the controller's gain for harmonics compensation, without the need for expert knowledge from the operator or the machine. This knowledge is required only once, at the step of defining the fuzzy sets, which should be performed by an expert. 
- Easy configuration of rules in the manner of linguistic description. This means that even if a required standard/grid code is changed, the rules can be easily updated. Such ability should be taken into account when planning future intelligent networks (smart grids or smart industry where smart devices should be implemented, e.g. smart transformer etc.).

- Help the human operator understand the physical meaning and effect of PI controller parameter changes in the SAPF. For example, as presented in this paper, the FL sets can translate complicated electrical relations between voltages and currents (phases, amplitudes, frequencies) to plain language.

- DSS based on FL can operate with significantly lower frequency $(2.5 \mathrm{kHz})$. It acts as a layer between the SAPF control algorithm and the operator, providing an easy-to-understand interface.

- The attenuation of current higher harmonics can be achieved very easily by a non-expert operator through a DSS. A case study in support of that has been presented.

- The DSS can be useful in the interaction between two machines, in case of the Internet of Things (IoT) or Internet of Everything (IoE) schemes, but this feature requires further investigation and will continue to be developed. It should be stressed that the presented results in the context of the DSS in IoT development are only preliminary. It is expected that the amount of data received by a human operator or a machine will be significantly reduced, thanks to conversion in the FL inference machine.

\section{REFERENCES}

[1] M. Cichowlas, PWM Rectifier with Active Filtering, $\mathrm{PhD}$ Thesis, WUT, 2004.

[2] M. Jasinski, G. Wrona, and S. Piasecki, "Chapter 3: Control of grid connected converter (GC) under grid voltage disturbances" in Advanced and Intelligent Control in Power Electronics and Drives, eds.T. Orłowska-Kowalska, F. Blaabjerg and J. Rodríguez, 91-142, Springer, 2014

[3] T. Płatek and T. Osypiński, "Current control with asymmetrical regular sampled pulse width modulator applied in parallel active filter", Bull. Pol. Ac.: Tech. 64 (2), 287-300 (2016).

[4] R. Teodorescu, M. Liserre and P. Rodriguez, Grid Converters for Photovoltaic and Wind Power Systems, Wiley, 2011.

[5] A. Keane, L. Ochoa, C. Borges, G. Ault, A. Alarcon-Rodriguez, R. Currie, F. Pilo, C. Dent and G. Harrison, "State-of-the-art techniques and challenges ahead for distributed generation planning and optimization", IEEE Trans. Power Systems 28 (2), 1493-1502 (2012).

[6] D. Das, "A fuzzy multiobjective approach for network reconfiguration of distribution systems", IEEE Trans. Power Delivery 21 (1), 202-209 (2006).

[7] R. Strzelecki and G. Benysek, Power Electronics in Smart Electrical Energy Networks, Springer, 2008.

[8] T. Kaczorek, "Positive time-varying continuous-time linear systems and electrical circuits", Bull. Pol. Ac:. Tech. 63 (4), 837-842 (2015).

[9] B. Ufnalski, L. M. Grzesiak, "Plug-in direct particle swarm repetitive controller with a reduced dimensionality of a fitness landscape - a multi-swarm approach", Bull. Pol. Ac: Tech. 63 (4), $857-866$ (2015)
[10] P. Pruski, S. Paszek, “Assessment of Polish Power System angular stability based on analysis of different disturbance waveforms", Bull. Pol. Ac:. Tech. 63 (2), 435-441 (2015).

[11] M. Magiera, "A multi-level method of support for management of product flow through supply chains", Bull. Pol. Ac: Tech. 63 (4), 933-946 (2015).

[12] M. Jasinski, M. Liserre, F. Blaabjerg and M. Cichowlas, "Fuzzy logic current controller for PWM rectifiers", IEEE Industrial Electronics, IECON 02 - 28th Annual Conf., 1300-1305 (2002).

[13] G. Tsengenes and G. Adamidis, "Shunt active power filter control using fuzzy logic controllers", IEEE International Symposium on Industrial Electronics (ISIE), 365-371 (2011).

[14] D. Qian, S. Tong, B. Yang, and S. Lee, "Design of simultaneous input-shaping-based SIRMs fuzzy control for double-pendulum-type overhead cranes", Bull. Pol. Ac:. Tech. 63 (4), 887-896 (2015).

[15] P. Witczak, M. Witczak, J. Korbicz, and Ch. Aubrun, "A robust predictive actuator fault-tolerant control scheme for TakagiSugeno fuzzy systems", Bull. Pol. Ac:. Tech. 63 (4), 977-987 (2015).

[16] P. Majtczak and S. Piasecki, "Shunt active power filter with fuzzy logic interface for harmonic reduction", Conf. Doctoral School of Energy and Geotechnology II, 134-140 (2015).

[17] S. Piasecki, R. Szmurło, and M. Jasinski, "Design of AC-DC grid connected converter using multi-objective optimization", Electrical, Control and Communication Engineering 5 (1), 11-19 (2014).

[18] M.B. Gorzałczany and F. Rudziński, "Handling fuzzy systems' accuracy-interpretability trade-off by means of multi-objective evolutionary optimization methods - selected problems", Bull. Pol. Ac:: Tech. 63 (3), 791-798 (2015).

[19] S. Mitchell, N. Villa, M. Stewart-Weeks, and A. Lange, "The Internet of Everything for Cities", http://ioeassess-ment.cisco.com/.

[20] PGE Dystrybucja S.A., Instrukcja Ruchu i Eksploatacji Sieci Dystrybucyjnej, 2013.

[21] P. Ferracci, "Power quality", Schneider Electric Cahier Tech. 199, 1-32 (2000).

[22] L. A. Zadeh, "Fuzzy sets", Information and Control 8 (3), 338-353 (1965).

[23] E. P. Dadios, Fuzzy Logic - Algorithms, Techniques and Implementation, InTech, 2012

[24] M. J. Patyra, D. M. Mlynek, Fuzzy Logic: Implementation and Applications, Wiley - Teubner, 1996.

[25] G. Viot, "Fuzzy logic in C", http://www.drdobbs.com/cpp/fuzzylogic-in-c/184408940, (1993).

[26] C. C. Lee, "Fuzzy logic in control systems: fuzzy logic controller, part II", IEEE Trans. Systems, Man and Cybernetics 20 (2), 419-435 (1990).

[27] T. Skulavik, M. Kopcek, P. Mydlo and P. Schreiber, "The defuzzification methods influence on fuzzy control of nuclear reactor", Int. Symposium Computational and Business Intelligence, 119-122 (2013).

[28] M. Jasiński, Direct Power and Torque Control of $A C / D C / A C$ Converter-Fed Induction Motor Drives, PhD Thesis, WUT, 2005.

[29] M. P. Kazmierkowski, M. Jasinski, and G. Wrona, "DSP-based control of grid-connected power converters operating under grid distortions", IEEE Trans. Ind. Informatics 7 (2), 204-211 (2011).

[30] A. Timbus, M. Liserre, R. Teodorescu, P. Rodriguez and F. Blaabjerg, "Evaluation of current controllers for distributed power generation systems", IEEE Trans. Power Electronic 24 (3), 654-664 (2009). 
[31] H. Akagi, E. H. Watanabe, and M. Aredes, Instantaneous Power Theory and Applications to Power Conditioning, Wiley, 2007.

[32] S. Piasecki, M. Jasinski, K. Rafał, A. Sikorski and A. Milicua, "Higher harmonics compensation in grid-connected PWM converters for renewable energy interface and active filtering", Przeglad Elektrotechniczny 87 (6), 85-90 (2011).

[33] S. Piasecki, M. Jasinski and A. Milicua, "Brief view on control of grid-interfacing AC-DC-AC converter and active filter under unbalanced and distorted voltage conditions", International Journal for Computation and Mathematics in Electrical and Electronic Engineering 30 (1), 351-373 (2011).

[34] S. Piasecki, M. Jasinski, G. Wrona and W. Chmielak, "Robust control of grid connected AC-DC converter for disturbed gener- ation", IEEE Industrial Electronics IECON - 38th Annual Conf. 5840-5845 (2012).

[35] M. Jasinski, M. Cichowlas and M. P. Kazmierkowski, "Direct control for $\mathrm{AC} / \mathrm{DC} / \mathrm{AC}$ converter-fed induction motor with active filtering function", COMPEL 25 (1), 235-243 (2006).

[36] S. Bhattacharya and D. Divan, "Synchronous frame based controller implementation for a hybrid series active filter system", IEEE Industry Applications Conf. IAS 3, 2531-2540 (1995).

[37] S. W. Smith, The Scientist and Engineer's Guide to Digital Signal Processing, California Technical Publishing, San Diego, 1999.

[38] W. H. Press, B. P. Flannery, S. A. Teukolsky, and W. T. Vetterling, Numerical Recipes in C: The Art of Scientific Computing Second Edition, Cambridge University Press, 1992. 